\title{
Sistem Monitoring Suhu Dan Kelembaban Lingkungan Berbasis Iot Dan Listrik Tenaga Surya
}

\author{
Abraham Heksa Martin ${ }^{1)}$, Hartono Pranjoto, Ph.D ${ }^{2)}$, Ir. Rasional Sitepu, M.Eng, IPM ${ }^{3)}$ \\ Jurusan Teknik Elektro, Faku ltas Teknik \\ Universitas Katolik W idya Mandala Surabaya, Jl. Kalijudan no. 37, Surabaya \\ ${ }^{1)}$ heksaabraham@gmail.com, ${ }^{2)}$ pranjoto@ukwms.ac.id, ${ }^{3)}$ s.rasional@gmail.com
}

\begin{abstract}
ABSTRAK
Kebutuhan pemantauan kondisi lingkungan jarak jauh untuk menjelaskan tentang kondisi lingkungan sekitar telah mendorong manusia untuk membuat alat pemantau berbasis IOT (Internet Of Things). Dua parameter kondisi lingkungan yang diukur dari beberapa data yang terdapat pada lingkungan adalah temperatur dan kelembaban. Pada tugas akhir ini, penulis merancang dan mengimplementasikan alat pemantau kondisi lingkungan dengan sensor suhu dan kelembaban menggunakan sensor DHT11.

Mikrokontroller ATMegal64 akan mencuplik data secara periodik kondisi lingkungan. Data yang didapat dari sensor DHT1 1 akan dikirimkan ke server internet dengan menggunakan modul GSM SIM808. Data yang diperoleh dari sensor DHT11 berupa nilai heksadesimal akan dikonversikan ke nilai desimal agar lebih mudah dibaca dalam tampilan laman (website) dengan domain yang telah diatur sebelumnya. Data yang telah dikirim akan disimpan dalam database. Lokasi pengukuran dapat diketahui dengan menggunakan modul GPS yang terintegrasi dalam modul GSM SIM808.

Data pengukuran suhu dan kelembaban serta lokasi pengukuran yang terpantau selama beberapa waktu, diharapkan dapat membantu untuk menyimpulkan situasi dan kondisi yang terjadi.
\end{abstract}

Kata kunci : Suhu, Kelembaban, Modul GSM \& GPS, Mikrokontroller.

\section{Pendahuluan}

Lingkungan memerlukan pemantauan untuk mengetahui kondisi yang terjadi, sehingga membutuhkan suatu sistem alat untuk dapat mengukur kondisi lingkungan tersebut. Dari antara banyak data lingkungan yang dapat diukur, dua diantaranya yang penting adalah tentang suhu dan kele mbaban lingkungan.

Saat ini sudah banyak alat ukur yang digunakan untuk mengetahui nilai suhu dan kelembaban lingkungan baik yang analog maupun digital. Alat ukur yang sudah ada di pasaran tersebut hanya sebatas menampilkan nilai suhu dan kelembaban pada layar display. Data yang ditampilkan adalah data yang diukur pada saat itu juga, selanjutnya data yang didapatkan tidak dapat diolah lebih lanjut untuk keperluan tertentu. Jika ingin mengetahui data suhu dan kelembaban yang lebih dari satu di berbagai lokasi, saat ini tidak ada alat ukur yang dapat memberi informasi lokasi tersebut. Dengan segala kelemahan tersebut, penulis menggunakan sensor DHT 11 yang dapat mengukur dua parameter suhu dan kelembaban. Data dari sensor ini dapat diolah lebih lanjut sesuai dengan keperluan yang diinginkan dan juga dapat diketahui lokasi pengukurannya.

Setelah mendapatkan data suhu dan kelembaban dengan mengakses tampilan laman (website), diperlukan juga untuk mengetahui posisi lokasi yang telah diukur kondisi lingkungannya. Untuk dapat mengetahui posisi tersebut, modul GSM ini terintegrasi dengan GPS. Pengguna akan mendapatkan data suhu dan kele mbaban selama beberapa waktu.

Masalah yang muncul dalam pengerjaan alat adalah :

1. Menampilkan data suhu dan kele mbaban pada web agar mudah dibaca oleh user, ditinjau dari output sensor DHT 11.

2. Mengirimkan data GPS ke web sehingga terlihat kondisi lo kasi sekitar

Agar sistem ini lebih spesifik dan terarah, maka pembahasan masalah dalam program ini memiliki spesifikasi alat sebagai berikut :

1. Mampu menampilkan data suhu dan kele mbaban berupa tabel pada web.

2. Menggunakan GPS pada modul SIM 808 untuk mendapatkan koordinat alat.

3. Menggunakan komunikasi GPRS untuk mengirimkan data ke database.

4. Pengambilan data dilakukan setiap 15 menit sekali.

5. Menggunakan minimum sistem mikrokontroller ATmega164 sebagai pengolah data.

6. Alat hanya dapat bekerja dengan baik jika berada di ruangan terbuka (mendapat sinyal GPS dan GSM).

7. Menggunakan sistem pembangkit listrik tenaga surya.

II. Landasan Teori 
Pada bab ini akan dibahas mengenai teori penunjang yang berkaitan dengan setiap peralatan elektronika dalam pengiriman, penerimaan, pengolahan dan penampilan data suhu dan kele mbaban serta untuk mengetahui posisi alat.

\section{II.1. Platform IoT}

Istilah IoT (Internet of Things) mulai dikenal tahun 1999 yang saat itu disebutkan pertama kalinya dalam sebuah presentasi oleh Kevin Ashton, cofounder and executive director of the Auto-ID Center di MIT. Menurut Ashton Internet of Things (IOT) didefinisikan sebagai sebuah teknologi yang memungkinkan adanya pengendalian, komunikasi, kerja sama dengan berbagai perangkat keras, berbagai data, memvirtualisasikan segala hal nyata ke dalam bentuk internet, dan lain-lain melalui jaringan internet. Internet of Things (IOT) adalah sebuah konsep yang bertujuan untuk memperluas manfaat dari konektivitas internet yang tersambung secara terus-menerus. Dengan semakin berkembangnya infrastruktur internet, maka kita menuju babak berikutnya, dimana bukan hanya smartphone atau komputer saja yang dapat terkoneksi dengan internet, melainkan berbagai macam benda nyata akan terkoneksi dengan internet. Sebagai contoh: mesin produksi, mobil, peralatan elektronik, peralatan yang dapat dikenakan manusia (wearables), dan termasuk benda nyata apa saja yang semuanya tersambung ke jaringan lokal dan global menggunakan sensor dan atau aktuator yang tertanam.

II.2. Sensor DHT11

DHT 11 memiliki keluaran sinyal digital yang sudah terkalibrasi dengan sensor suhu dan kelembaban yang lama. Teknologi ini memiliki kehandalan tinggi dan stabilitas yang baik dalam jangka panjang. Sensor ini termasuk elemen resistif dan perangkat pengukur suhu NTC, memiliki kualitas yang sangat baik, respon cepat, kemampuan anti-gangguan dan harga yang murah.

Setiap elemen DHT 11 telah dikalibrasi di laboratorium yang sangat akurat pada kalibrasi kele mbaban. Koefisien kalibrasi disimpan sebagai program dalam memori OTP, yang digunakan oleh proses mendeteksi sinyal internal sensor. Antarmuka serial satu jalur membuat integrasi sistem cepat dan mudah. Uku rannya yang kecil, konsumsi daya yang rendah dan jangkauan transmisi sinyal mencapai 20 meter. DHT11 Terdiri dari 4-pin output.

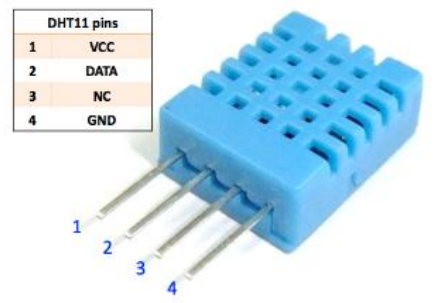

Gambar 1. Sensor DHT 11

\section{II.3. AT-Mega164}

Mikrokontroler

ATMega164PA

digunakan sebagai pengontrol utama alat tersebut. ATMega164PA mempunyai fitur khusus UART 2 kanal. Agar mikrokontroler ini dapat bekerja, maka diperlukan rangkaian pendukung diantaranya rangkaian reset dan rangkaian external crystal oscillator. Mikrokontroller ATMega164 memiliki 44 buah pin, terdiri dari 32 port yang dibagi menjadi 4 yaitu port A, port B, port $\mathrm{C}$ dan port $\mathrm{D}, 3$ pin $\mathrm{VCC}, 4$ pin ground, 1 AVCC , 1 pin reset, 2 pin eksternal kristal osilator dan 1 Aref. ATMega 164 memiliki memori flash sebesar 16Kbytes, EEPROM sebesar 512 bytes, dan RAM 1 Kbytes.
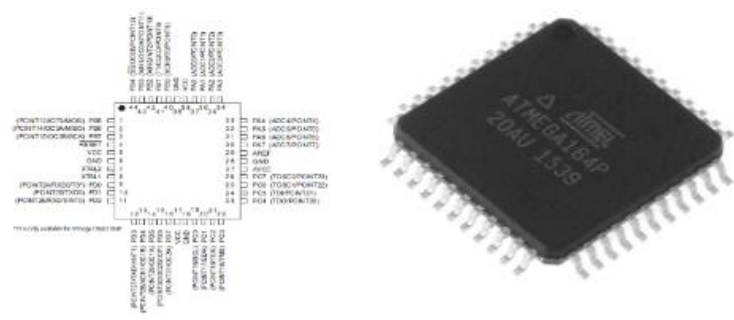

Gambar 2. Konfigurasi Pin \& Tampak Fisik ATMega164

\section{II.4. SIM808}

SIM808 me miliki 3 buah fitur yaitu untuk bluetooth, GPS dan juga GPRS. Bluetooth berguna untuk koneksi transfer data dengan device lain. GPS berguna untuk mengetahui lokasi alat. GPRS berguna untuk menghubungkan mikrokontroller dengan jaringan internet sebagai pengirim data.

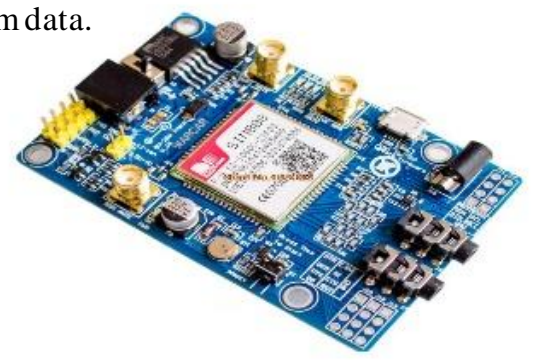

Gambar 3. Bentuk Fisik SIM808

\section{II.5. Protokol Komunikasi}

Protokol adalah seperangkat aturan yang mengatur pembangunan koneksi komunikasi, perpindahan data, serta penulisan hubungan antara dua atau lebih perangkat komunikasi. Protokol dapat berupa perangkat keras, perangkat lunak atau kombinasi dari keduanya. Protokol distandarisasi oleh International Standard Organization (ISO) dalam sebuah Open System Interconnection (OSI).

\section{II.6. Tampilan Data Pada Website}

Website merupakan kumpulan halaman web yang saling terhubung dan file-filenya saling terkait. Web terdiri dari page atau halaman, dan kumpulan halaman yang dinamakan homepage. Homepage berada pada posisi teratas, dengan 
halaman - halaman terkait berada di bawahnya. Biasanya setiap halaman di bawah homepage disebut child page, yang berisi hyperlink ke halaman lain dalam web.

\section{II.7. Google Maps}

Google Maps adalah dasar pemetaan web dan teknologi aplikasi layanan yang disediakan oleh Google, gratis (untuk non-komersial). Di dalam Google Maps menawarkan peta jalan, sebuah rute rencana untuk bepergian dengan berjalan kaki, mobil, atau angkutan umum dan pemantau bisnis di perkotaan untuk beberapa negara di sekitar dunia. Menurut salah satu pencipta (Las Rasmussen),Google Maps adalah suatu cara untuk mengorganisasikan informasi di dunia secara geografis. Seperti banyak aplikasi web Google lainya, Google Maps menggunakan JavaScript secara ekstensif.

\section{II.8. Panel Surya}

Panel surya adalah alat yang terdiri dari sel surya yang mengubah cahaya menjadi listrik. Mereka disebut surya atau matahari atau "sol" karena matahari merupakan sumber cahaya terkuat yang dapat dimanfaatkan. Panel surya sering kali disebut sel photovoltaic, photovoltaic dapat diartikan sebagai "cahaya listrik". Sel surya bergantung pada efek photovoltaic untuk menyerap energi.

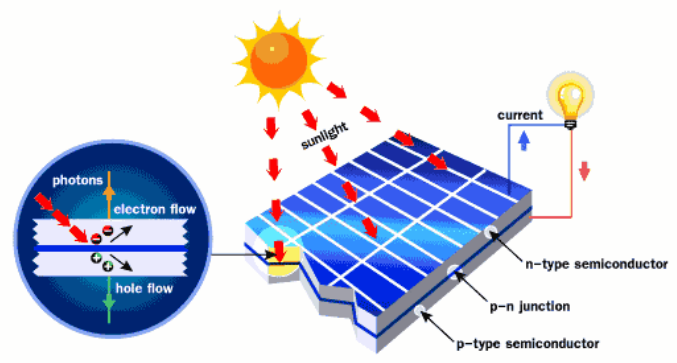

Gambar 4. Proses Energi Panel Surya

\section{II.9. Baterai (Accu)}

Accumulator atau sering disebut aki, adalah salah satu komponen utama dalam kendaraan bermotor, baik mobil atau motor, semua memerlukan aki untuk dapat menghidupkan mesin mobil (mencatu arus pada dinamo stater kendaraan). Aki mampu mengubah tenaga kimia menjadi tenaga listrik. Aki untuk mobil biasanya mempunyai tegangan sebesar 12 Volt, sedangkan untuk motor ada tiga jenis yaitu, dengan tegangan 12 Volt, 9 volt dan ada juga yang bertegangan 6 Volt. Selain itu juga dapat ditemukan pula aki yang khusus untuk menyalakan tape atau radio dengan tegangan juga yang dapat diatur dengan rentang 3, 6, 9, dan 12 Volt.

\section{II.11. Battery Charge Controller}

Battery Charge Controller (BCR) merupakan pengendali masukan atau peregulasi batas rentang masukan untuk pengisian atau pelepasan arus dari baterai. BCR akan mencegah pengisian berlebih dan mencegah tegangan berlebih, yang dapat membuat performa dan usia baterai berkurang, selain itu juga dapat menimbulkan resiko keamanan. BCR juga dapat mencegah baterai untuk tidak terlalu kosong dalam proses pengeluaran daya ("pengosongan dalam"), atau melakukan pengontrolan dalam pelepasan arus dan daya, bergantung pada teknologi baterai, untuk melindungi daya tahan baterai.

\section{II.10 GPS \\ GPS adalah singkatan dari Global} Positioning System yang merupakan sistem untuk menentukan posisi dan navigasi secara global dengan menggunakan satelit dan metode Triangulasi. Sistem tersebut merupakan sistem yang pertama kali dikembangkan oleh Departemen Pertahanan Amerika yang awalnya diperuntukan bagi kepentingan militer. NA VSTAR GPS (Navigation Satellite Timing and Ranging Global Positioning System) adalah nama asli dari Sistem GPS, yang mempunyai tiga segmen yaitu : satelit (Space Segment), pengendali (Control Segment), dan penerima/pengguna (User Segment). Satelit GPS yang mengorbit bumi seluruhnya berjumlah 24 buah, 21 buah aktif bekerja dan 3 buah sisanya adalah cadangan. Satelit ini bertugas untuk menerima dan menyimpan data yang ditransmisikan oleh stasiun-stasiun pengendali, menyimpan dan menjaga informasi waktu berketelitian tinggi (jam atomic di satelit), dan memancarkan sinyal serta informasi secarakontinyu ke perangkat penerima (receiver).

\section{Metode Penelitian}

Rancangan keseluruhan alat dapat dilihat pada Gambar 5 .

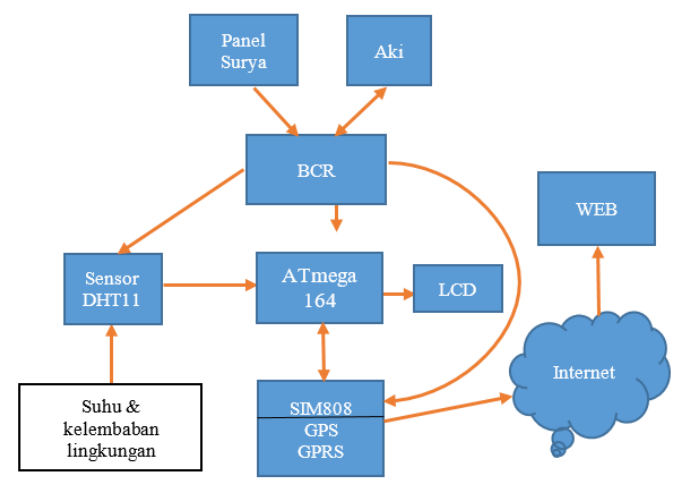

Gambar 5. Diagram Blok Alat

\section{III.1. Cara Kerja Alat}

Berikut ini adalah urutan cara kerja alat Pada sistem alat ini menggunakan power supply dari dua sumber yaitu panel surya dan aki. Kedua sumber ini akan dipilih salah satu oleh Battery Charge Controller (BCR) yaitu menggunakan sumber daya dari aki yang selanjutnya dihubungkan ke sistem alat antara lain sensor DHT 11, mikrokontroller ATmega164 dan modul 
SIM808. Pada saat panel surya mendapat cahaya sinar matahari yang cukup banyak maka BCR akan menggunakan daya panel surya untuk charge aki. Jika kurang mendapat cahaya sinar matahari maka BCR akan tetap menggunakan aki sebagai sumber dayanya.

Alat ini akan terpasang pada lingkungan terbuka yang akan mengukur parameter suhu dan kelembaban lingkungan. Nilai suhu dan kelembaban lingkungan di sensing oleh sensor DHT11. Output sensor DHT11 yang berupa data heksadesimal akan diterima oleh mikrokontroller ATmega164 pada pin dig ital.

Pada SIM808 terdapat modul GPS dan GPRS. Data yang diterima dari mikrokontroller melalui koneksi serial akan dikirimkan ke server melalui jaringan internet GPRS dengan periode pengiriman selama 15 menit sekali. Server akan menerima data dan menyimpan data yang diterima di database. Untuk mengetahui posisi koordinat alat digunakan GPS yang menjadi satu modul dengan SIM808. Pengiriman posisi in $\mathrm{i}$ juga menggunakan jaringan internet GPRS.

Setelah SIM808 dapat mengirim data suhu dan kelembaban serta posisi koordinat alat melalui internet, maka data akan ditampilkan pada web. Selanjutnya sistem akan mematikan GPS dan GPRS untuk menghe mat daya. Pada saat satu men it sebelum pengiriman data, sistem akan menghidupkan kembali GPS dan GPRS agar dapat mengirim data selanjutnya. Website akan mengolah data yang ada di database dengan menggunakan HTMLdan PHP.

\section{III.2. Sensor DHT11}

Sensor suhu dan kelembapan DHT11 merupakan sensor untuk mensensing objek suhu dan kelembaban pada 1 modul yang dimana memiliki output sinyal digital yang sudah terkalibrasi. Module sensor ini tergolong kedalam elemen resistif seperti perangkat pengukur suhu seperti contohnya yaitu NTC. Keunggulan dari sensor DHT11 dibanding dengan yang lainnya antara lain memiliki kualitas pembacaan data sensing yang sangat baik, respons if (cepat dalam pembacaan kondisi ruangan) serta tidak mudah terinterverensi. Output sensor DHT11 dihubungkan mikrokontroller pada PINC.0 untuk dapat diproses datanya.

\section{III.3. Modul SIM808}

Modul ini digunakan untuk menerima data pengukuran suhu dan kelembaban dari mikrokontroller dengan jalur koneksi serial UART. Pin RX \& TX SIM 808 terhubung dengan PIND.0 \& PIND.1 pada mikrokontroller. Data yang sudah diterima akan di unggah melalui jaringan internet GPRS ke web. Tampilan pada web akan berupa tabel. Modul SIM808 juga berfungsi untuk mendapatkan posisi koordinat alat dengan menggunakan GPS. Posisi koordinat akan ditampilkan dengan tampilan maps pada web.

\section{III.4. Panel Surya}

Pada skripsi ini digunakan panel surya silicon solar PV module sebesar $10 \mathrm{Wp}$ untuk mencukupi keperluan daya tersebut dan untuk charge aki, dimana setiap $10 \mathrm{Wp}$ yang dapat menghasilkan maksimal tegangan sebesar 21 Volt dan arus maksimal sebesar 0,66 A. Perhitungan untuk panel surya yang diperlukan akan dije laskan sebagai berikut.

- 1 Buah solar panel $=0,66$ A.

- Di Indonesia durasi energi matahari yang bisa dikonversi menjadi energi listrik selama 5 jam / hari; 0,66 A x 5 jam = 3,3 Ah. Dari perhitungan tersebut didapatkan energi 3,3 Ah cukup untuk mengisi aki sebesar $3 \mathrm{Ah}$.

- Dengan minimum pengisian sebesar $20 \%$ dari kapasitas aki berarti :

Aki $=3$ Ampere, $20 \% \times 3 \mathrm{~A}=0,6$ Ampere; $3 \mathrm{Ah} /$ $0,6 \mathrm{~A}=5 \mathrm{Jam}$

Dari perhitungan diatas dapat dianalisa bahwa untuk dapat mengisi ulang aki dibutuhkan selama 5 jam/ hari.

\section{III.5. Accumulator (Aki)}

Pada alat ini aki berfungsi sebagai sumber tegangan untuk menghidupkan sebuah beban. Dalam alat ini menggunakan sumber aki 1 buah dengan kapasitas $12 \mathrm{~V} / 3$ A. Jika aki diberi beban sebesar 0,355 watt (sesuai pengukuran di Bab 4), maka aki dapat menyuplai beban tanpa pengisian daya selama 50,7 jam.

\section{III.6. Perancangan Website}

Agar user dapat dengan mudah melihat data yang telah dikirim oleh device maka perlu dibuat interface dalam bentuk aplikasi halaman berbasis WEB.

Terdapat beberapa halaman web yang saling bekerja sama agar informasi dapat sampai kepada user. Diantaranya adalah halaman Sim808.php untuk mengambil data suhu, kelembaban, latitude dan longitude yang telah dikirim oleh modul SIM 808 .

Selanjutnya ada halaman web vtable.php yang berfungsi untuk mengambil data terbaru di dalam database. Setelah mendapat data tersebut, pada halaman web vtable.php menampilkan data dalam bentuk tabel. Pada halaman web vtable.php ini terdapat timer untuk autorefresh selama 15 menit. Dalam fungsi autorefresh, program akan mengambil dan menampilkan data terbaru yang telah masuk pada database

III.7. Perancangan Struktur Data pada
MySQL
Perancangan ini bertujuan agar data
dapat disimpan sesuai dengan kebutuhan. Terdapat data yang ingin dilihat dan disimpan yaitu suhu dan kelembaban karena perubahan yang perlu diperhatikan, juga membutuhkan data GPS dengan parameter latitude dan longitude yang diambil. Dengan demikian dibuat database 
nama "ahmr3137_ahmweb96" dan tabel nama "s ensor_log".

\section{Hasil Penelitian dan Pembahasan}

Pada bab ini akan membahas mengenai mekanis me pengujian alat, serta pengujian alat yang dilakukan untuk mengetahui kinerja dari alat. Secara umum pengujian alat "Sistem Monitoring Suhu dan Kelembaban Lingkungan berbasis IoT dan Listrik Tenaga Surya" in i meliputi: pengujian GPRS dan GPS modul SIM808, pengukuran konsumsi energi alat, pengujian pengiriman data ke Database MySQL, pengujian Sensor DHT 11.

\section{IV.1. SIM808 GPRS \& GPS}

Untuk melakukan pengujian komunikasi data menggunakan modul SIM808 (GPRS \& GPS) dibutuhkan beberapa command spesifik untuk dapat melakukan pertukaran data antara mikroprosesor dan internet. Pengujian pengiriman data dari modul SIM808 ke mikrokontroler bertujuan untuk menguji komunikasi data UART TTL antara modul SIM808 dengan mikrokontroler. Komputer melihat data tersebut menggunakan program termite.exe dengan tujuan mengetahui data-data yang diterima dari modul SIM808.

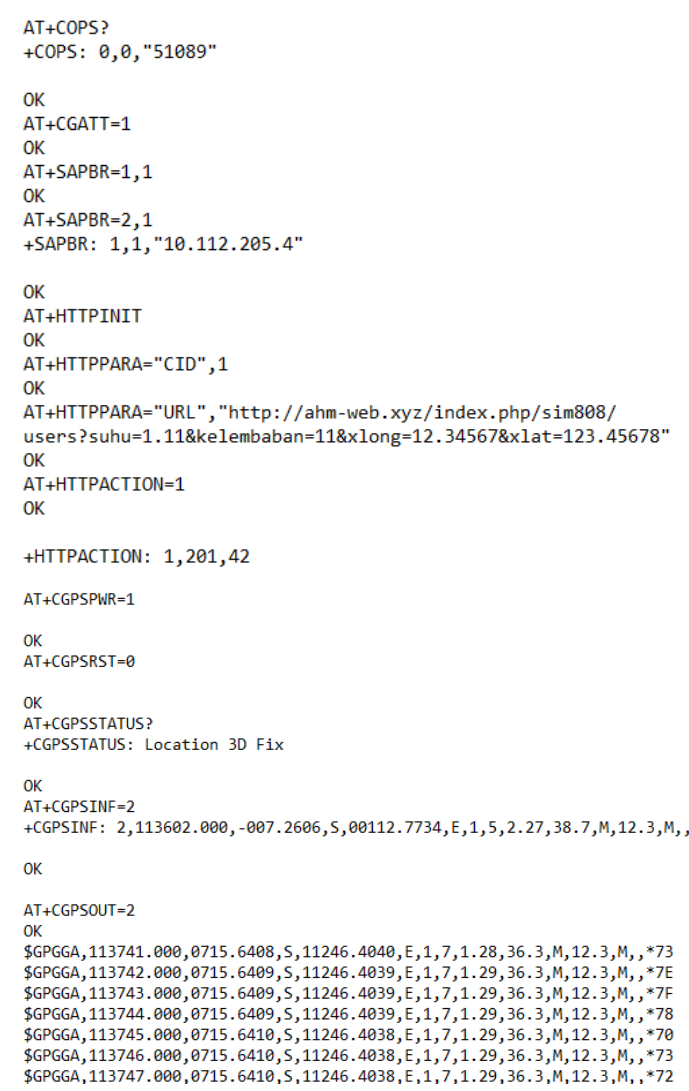

Gambar 6. Pengujian GPRS \& GPS pada SIM 808

\section{IV.2. Pengukuran Konsumsi Energi}

Saat mikrokontroler aktif, modul SIM808 standby (GPRS \& GPS OFF) konsumsi arus yang dibutuhkan adalah 67,2 mA sedangkan pada saat mikrokontroller aktif, modul SIM808 aktif (GPRS \& GPS ON) maka arus total men ingkat menjadi $104 \mathrm{~mA}$. Saat modul SIM808 aktif, modul ini melakukan komunikasi GPRS mengirim data ke server. Konsumsi energi dari alat tersebut adalah perkalian antara tegangan dan arus yang dikonsumsi serta waktu digunakan.

Pada perhitungan menggunakan rasio dalam mengetahui konsumsi energinya. Rumus rasio yang digunakan untuk mengukur energi seperti pada persamaan 4.1 .

Energ $\mathrm{i}=($ Tegangan $($ Arus Standby $\mathrm{x}$ Waktu + Arus Kirim Data x Waktu) )/(Total Waktu) (4.1)

Maka konsumsi energ i dari alat adalah:

Energ $\mathrm{i}=(5,1 \mathrm{~V}(67,2 \mathrm{~mA} \times 14+104 \mathrm{~mA} \times 1)$ )$/(14+1) \mathrm{Wh}$

Total Energi $=0,3552 \mathrm{Wh} \approx 355 \mathrm{mWh}$

\section{IV.3. Pengukuran Konsumsi Energi}

Pengujian pengiriman data ke database bertujuan untuk menguji penulisan data pada database yang terdapat di dalam server. Data yang dikirim merupakan data-data suhu, kelembaban, GPS yang telah di proses oleh mikrokontroler sehingga didapatkan data diantaranya nilai suhu, nilai kelembaban, nilai latitude dan nilai longitude.

Pada saat modul sudah terkoneksi dengan server melalui komunikasi GPRS maka mikrokontroler akan mengirimkan perintah AT+HTTPACTION=1 untuk memulai pengiriman data. Protocol HTTP digunakan untuk dapat membuka file Sim808.php yang tersimpan pada server oleh karena data yang dikirimkan menjadi POST/ (diikuti halaman web yang dituju dan data-data yang akan disimpan) HTTP/1.1 Host:ahm-web.xyz. Jika data telah berhasil diterima maka server akan membalas modul GSM dengan pesan HTTP/1.1 201 OK.

Data yang telah masuk dapat dilihat pada database. Dengan demikian dapat dikatakan bahwa modul GSM dapat melakukan koneksi GPRS dengan serverserta menyimpan data tersebut ke dalam database.

\section{IV.4. Pengujian Tampilan Halaman Web}

Tampilan pada halaman web ini berupa grafik yang berisikan data yang diambil yaitu suhu, kelembaban, longitude, latitude dan waktu serta tanggal pengambilan datanya. Domain alamat web dapat dibuka di ahm-web.xyz. Terdapat beberapa pilihan dalam menampilkan datanya. Data dapat ditampilkan dari $10-100$ data dengan pilihan $10,25,50,100$. Data yang ditampilkan mulai dari yang paling terbaru ke yang paling lama. Tampilan akan diperbaharui selama 15 menit sekali dengan menggunakan autorefresh agar data yang terbaru dapat masuk. 
Gambar 7. Grafik Nilai Suhu dan Kelembaban

IV.5. Perbandingan Hasil Pengambilan Data

Perbandingan hasil pengambilan dilakukan dengan menggunakan 2 variabel yaitu nilai yang dikeluarkan dari LCD mikrokontroller dan barang pabrik yang telah jadi. Data yang dibandingkan adalah suhu dan kelembaban. Pada Tabel 4.4 merupakan perbandingan hasil suhu dan kelembaban dari output sensor DHT11 dengan alat ukur pabrik CX-202. Data yang diambil sebanyak 10 data sebagai sample.

Tabel 1. Perbandingan Suhu dan Kelembaban

\begin{tabular}{|c|c|c|c|c|c|c|}
\hline No & $\begin{array}{c}\text { Suhu } \\
\text { DHT11 }\end{array}$ & $\begin{array}{c}\text { Subu } \\
\text { CX202 }\end{array}$ & $\begin{array}{c}\% \\
\text { Deviasi }\end{array}$ & $\begin{array}{c}\text { Kelembabann } \\
\text { DHT11 }\end{array}$ & $\begin{array}{c}\text { Kelembaban } \\
\text { CX202 }\end{array}$ & $\begin{array}{c}\% \\
\text { Deviasi }\end{array}$ \\
\hline 1 & 30,4 & 30,6 & 0,65 & 54,0 & 52,0 & 3,84 \\
\hline 2 & 31,2 & 30,8 & 1,29 & 56,0 & 54,0 & 3,70 \\
\hline 3 & 31,2 & 30,8 & 1,29 & 56,0 & 54,0 & 3,70 \\
\hline 4 & 31,1 & 30,6 & 1,63 & 56,0 & 55,0 & 1,81 \\
\hline 5 & 31,2 & 30,8 & 1,29 & 56,0 & 54,0 & 3,70 \\
\hline 6 & 31,1 & 31,0 & 0,32 & 54,0 & 52,0 & 3,84 \\
\hline 7 & 31,1 & 30,8 & 0,97 & 52,0 & 52,0 & 0 \\
\hline 8 & 30,8 & 30,7 & 0,32 & 50,0 & 48,0 & 4,16 \\
\hline 9 & 30,7 & 30,8 & 0,32 & 52,0 & 49,0 & 6,12 \\
\hline 10 & 30,9 & 30,8 & 0,32 & 55,0 & 53,0 & 3,77 \\
\hline Mean & 30,9 & 30,7 & 0,84 & 54,1 & 52,3 & 3,46 \\
\hline
\end{tabular}

Pada Tabel 1. dapat dianalisa perbedaan selisih data yang diambil dari kedua alat. Parameter suhu dengan deviasi rata-rata sebesar $0,84 \%$ dan parameter kele mbaban dengan deviasi rata-rata sebesar 3,46\%. Pada sensor DHT11 ini dapat diketahui bahwa nilai suhu lebih akurat dibandingkan nilai kelembaban yang terukur pada sensor. Menurut akurasi pengukuran dari spesifikasi yang diberikan, suhu pada $25^{\circ} \mathrm{C}$ sebesar $\pm 2^{\circ} \mathrm{C}$ dan kelembaban pada suhu $25^{\circ} \mathrm{C}$ sebesar $\pm 5 \%$ RH. Dengan mengacu pada akurasi dari spesifikasi yang ada, sensor ini masih bekerja dengan baik dalam hasil pengukurannya tidak melebihi batas penyimpangan pengukuran.

\section{Kesimpulan}

Dari hasil perancangan, pembuatan dan pengujian alat yang telah dilakukan, penulis dapat mengambil kesimpulan sebagai berikut:

a. Mikrokontroller dapat bertukar data dengan modul SIM808 (GPRS dan GPS) menggunakan komunikasi serial UART 9600 bps serta terhubung dengan server menggunakan GPRS.

b. Alat dapat mengirim data suhu, kelembaban, lokasi koordinat latitude dan longitude ke server. c. Halaman web dapat menampilkan tabel berisi data suhu, kelembaban, latitude, longitude, tanggal dan waktu penerimaan data. Pada tabel dapat disesuaikan banyaknya data yang ditampilkan dari 10 - 100 data.

d. Jangkauan sinyal GPS sangat mempengaruhi jumlah satelit yang dapat diterima sehingga lokasi koord inat dapat tepat jika jumlah satelit yang didapatkan lebih dari 8 buah satelit.

e. Jangkauan sinyal GPRS sangat me mpengaruhi lama atau cepatnya serta keberhasilan pengiriman data ke server

\section{DAFTAR PUS TAKA}

[1] Platform IoT, https://www.acade mia.edu/19681203/Intern et_of_Things_IoT_

(diakses tanggal 28 Nove mber 2017)

[2] Sensor DHT 11, https ://akizu kidens hi.com/down load/ds/aoso ng/DHT11.pdf (diakses tanggal 5 Nove mber 2017)

[3] Mikrokontroller ATmega 164, Atmel . 2017. "8-bit Atmel Microcontroller with 16/32/64/128K Bytes In-System Programmable Flash Datasheet"

[4] Modul SIM808. SIMCom . 2017. "SIM 800 Series AT Command Manual" Versi1.09 Shanghai:SIMCo $\mathrm{m}$ W ire les s Solutions Ltd.

[5] Protokol Komunikasi. Noldus, Rogier . 2006. "Intellegent Networks for the GSM, GPRS and UMTS Network" England:John Wiley \& Sons.

[6] Display Website, Nixon, Robin . 2009. "Learning PHP,MySQL, and Javascript" United States of America:O'Reilly Media, Inc.

[7] Google Maps. Pangaliela, Egber . 2016. "Sistem Pengaman Kendaraan dengan Menggunakan Metode Geofence pada Google Maps" Skripsi, Universitas Katolik Widya Mandala Surabaya

[ 8 ] Panel Surya. http://digilib.unimus.ac.id/files/disk1/149/jtp tunimus-gdl-efendiabdu-7401-3-babii.pdf (diakses tanggal 25 Nove mber 2017)

[9] Accu \& Battery Charge Controller. Rahman, Shusmita, dkk. 2012. Design of a Charge Controller Circuit with Maximum Power Point Tracker (MPPT) for Photovoltaic System. BRAC University.

[10] Global Positioning System. Pranjoto, H., Agustine, L, Susilo, Y.S., Tehuayo, R., "GPS Based Vehicle Tracking over GPRS for Fleet Management and Passenger/ Payload/ Vehicle Security", ARPN Journal of Engineering and Applied Sciences, Vol. 9, No. 11. 